\title{
ENSINO DE EMPREENDEDORISMO E POTENCIAL EMPREENDEDOR EM UMA INSTITUIÇÃO DE ENSINO SUPERIOR
}

Marta Bendor ${ }^{1}$

Fernando César Lenzi ${ }^{1}$

Antonia Márcia Rodrigues Sousa ${ }^{2}$

\footnotetext{
${ }^{1}$ Universidade do Vale do Itajaí

${ }^{2}$ Universidade Federal de Mato Grosso do Sul
} 


\section{ENSINO DE EMPREENDEDORISMO E POTENCIAL EMPREENDEDOR EM UMA INSTITUIÇÃO DE ENSINO SUPERIOR}

Resumo: O objetivo deste estudo é analisar a contribuição do ensino de empreendedorismo, no desenvolvimento do potencial empreendedor, segundo o índice Carland Entrepreneurship Index (CEI), proposto por Carland, Carland e Hoy (1992), composto por quatro dimensões: postura estratégica; propensão à inovação, propensão ao risco e traços de personalidade. Por meio destas, os indivíduos são classificados em: microempreendedor; empreendedor; e macro empreendedor. Foram pesquisados 171 discentes de Administração de uma IES privada. Trata-se de uma pesquisa quantitativa de natureza descritiva e documental, seguida por uma survey. Com a Análise de Variância (ANOVA), buscou-se identificar características do perfil do indivíduo, que propiciassem determinado potencial empreendedor. Os resultados não apresentaram diferenças estatísticas entre os níveis de potencial empreendedor dos respondentes, sendo 84,67\% dos indivíduos classificados como empreendedores, $10,67 \%$ microempreendedores e 4,67\% macros empreendedores. Estes achados corroboram com estudos anteriores onde o CEI foi aplicado em contextos diversos, contribuindo para a consolidação deste enfoque teórico.

Palavras-chave: Empreendedorismo. Ensino de empreendedorismo. Potencial empreendedor.

\section{Introdução}

Estudos sobre a contribuição do empreendedorismo para o crescimento e desenvolvimento econômico demonstram como positiva a influência da cultura empreendedora neste processo dentro da sociedade. No entanto, para gerar esta contribuição, os indivíduos considerados empreendedores enfrentam enormes desafios que precisam explorar como oportunidade, transformando o ato de empreender na geração de resultados concretos, com muita disciplina e persistência (SCHUMPETER, 1934; MCCLELLAND, 1972; CARREE; THURIK, 2003; HISRICH; PETERS; SHEPHERD, 2014).

Visando preparar os indivíduos para o ato de empreender, tanto no que diz respeito à percepção de oportunidades, geração de ideias e enfrentamento de desafios, o ensino de empreendedorismo encontra-se como aliado nesta seara e este tem sido tema frequente nos estudos recentes sobre este campo da educação universitária (COUTO; MARIANO; MAYER, 2010; HECKE, 2011; FONTENELE; BRASIL; SOUSA, 2012; ROCHA; FREITAS, 2014; LIMA et al., 2014).

No entanto, mesmo contando com preparação, empreender é um processo complexo baseado em múltiplas variáveis, sendo possível classificar como empreendedor um indivíduo com postura inovadora, que ao utilizar determinada estratégia, desenvolve um negócio visando crescimento e consequente lucro. Desta forma, considerando que o nível de empreendedorismo se constitui como uma variável subjetiva torna-se difícil estabelecer uma
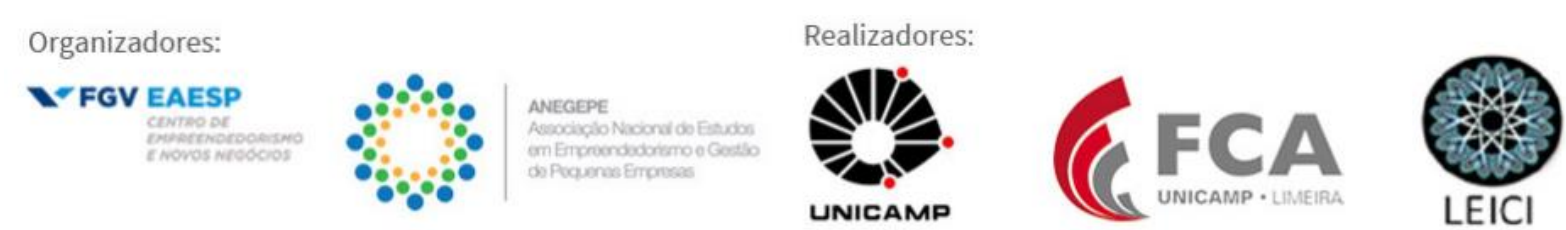
ferramenta que quantifique o nível de empreendedorismo dos indivíduos considerados empreendedores (INÁCIO JÚNIOR; GIMENEZ, 2004).

Dentre os métodos existentes, é possível destacar o Carland Entrepreneurship Index CEI de Carland, Carland e Hoy (1992). Segundo este método, o empreendedorismo é função de quatro elementos fundamentais: postura estratégica, propensão à inovação, traços de personalidade (que envolve necessidade de realização e criatividade) e propensão ao risco. À luz da escala CEI os indivíduos são classificados em três categorias: microempreendedor, empreendedor e macro empreendedor, conforme a presença dos quatro elementos anteriormente descritos (INÁCIO JÚNIOR; GIMENEZ, 2004).

Diante da necessidade de formação dos atuais e futuros empreendedores, visto que o desenvolvimento do empreendedorismo nos estudantes de Administração apresenta-se como forma de contribuição para a economia e desenvolvimento da cidadania, as instituições de ensino superior assumem papel fundamental ao prover espaços de encontros de oferta e demanda de conteúdos que estimulem o desenvolvimento de competências empreendedoras, (HENRIQUE; CUNHA, 2008; ANDREASSI; FERNANDES, 2010; SILVA, 2010; RIBEIRO; BERNARDES, 2014).

Considerando que a formação empreendedora tem uma característica multidisciplinar, para que os diferentes objetivos sejam alcançados, é necessário estabelecer um plano que adapte a metodologia de ensino ao contexto da aprendizagem esperada. Sob esta ótica, diferentes opções de métodos, técnicas e recursos são encontradas na literatura como forma de se promover o processo de ensino-aprendizagem da formação empreendedora (BOYLES, 2012; HONIG, 2004; KURATKO, 2005; DEGEN, 2009; ILANDER, 2010; KNOTTS, 2011; SCHMIDT; SOPER; FACCA, 2012).

Desta forma, a pergunta norteadora do presente estudo é: Qual a contribuição do ensino de empreendedorismo para o desenvolvimento do potencial empreendedor dos estudantes do curso de administração de uma instituição de ensino superior no Ceará, sob a ótica do Carland Entrepreneurship Index? Objetivando responder a esse questionamento, o objetivo geral traçado é analisar a contribuição do ensino de empreendedorismo no desenvolvimento do potencial empreendedor dos estudantes, do curso de administração, de uma instituição de ensino superior privada no Ceará. E, como objetivos específicos: identificar o perfil dos alunos pesquisados; categorizar as estratégias de ensino das disciplinas que abordam a temática de empreendedorismo no curso e, por fim, classificar o potencial empreendedor dos alunos segundo a escala CEI (Carland Entrepreneurship Index).

A contribuição deste trabalho apresenta-se no sentido de propor mudanças nas grades curriculares e oportunizar direcionamentos aos cursos universitários em relação a práticas que contribuam parra a formação de novos empreendedores, por meio da oferta de conteúdos e práticas que estimulem o desenvolvimento de competências empreendedoras (HECKE, 2011; RIBEIRO; BERNARDES, 2014). Além do aspecto da formação, faz-se necessário compreender os aspectos que o indivíduo já carrega consigo a exemplo do potencial empreendedor. Para Carland e Carland (1996), todo indivíduo apresenta potencial empreendedor. E, ao desenvolvê-lo, é capaz de identificar oportunidades e fazer uso de sua criatividade visando transformá-las em negócios, assumindo riscos para obtenção do sucesso.

O estudo foi dividido em duas etapas: na primeira etapa foi realizada uma pesquisa descritiva e documental, de abordagem qualitativa e a segunda etapa, de abordagem

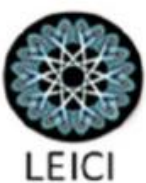


quantitativa, fez uso da estratégia de survey, com aplicação de questionários junto a uma amostra de 171 discentes do curso de Administração de uma IES no interior do Ceará. Para análise quantitativa dos dados, foi utilizada a análise descritiva e a técnica estatística de Análise de Variância (ANOVA), visando responder à questão norteadora deste estudo. A sequência do artigo está assim estruturada: referencial teórico sobre ensino de empreendedorismo e potencial empreendedor, descrição dos procedimentos metodológicos, discussão dos resultados e considerações finais, onde também são apresentadas as limitações deste estudo e sugestões para futuras pesquisas.

\section{Referencial Teórico}

Com propósito de discutir o arcabouço teórico fundamental e suas contribuições relevantes, o referencial teórico é apresentado a seguir, iniciando por ensino de empreendedorismo, seguindo com potencial empreendedor e os desdobramentos do estudo de Carland, Carland e Hoy (1992), com seu modelo conceitual de classificação do empreendedor em categorias, o método CEI - Carland Entrepreneurship Index.

\subsection{Ensino de Empreendedorismo}

A essência do ensino superior consiste na transmissão e disseminação de conhecimento, deve-se a isto sua importância junto à sociedade. Bernheim e Chauí (2008) destacam que o crescimento deve ser o principal paradigma a ser seguido pela educação superior. Neste sentido, os mesmos autores afirmam que é necessário buscar um desenvolvimento baseado em nossas próprias forças produtivas, capacidades e na competitividade a serviço da dignidade do ser humano.

Alinhado a esta concepção, o desenvolvimento do empreendedorismo nos estudantes de Administração apresenta-se como forma de contribuição para a economia e desenvolvimento da cidadania. Além disto, a dificuldade de obter um emprego formal, necessidade de desenvolver competências e habilidades, aumento no volume de horas trabalhadas nas grandes corporações e busca por uma melhor qualidade de vida, fizeram com que os indivíduos passassem a enxergar o empreendedorismo uma alternativa de carreira (HENRIQUE; CUNHA, 2008; ANDREASSI; FERNANDES, 2010).

O ensino de empreendedorismo pressupõe a vivência, adaptação e experimentação, de forma que o aluno seja inserido em contextos reais para que este compreenda a dinâmica de um empreendimento e seja preparado para vivenciar as diversas situações com as quais se deparará em sua realidade empreendedora. Neste sentido, alguns métodos que privilegiam a prática enquanto metodologia de ensino, como os estudos de caso e os jogos empresariais são indicados, além de palestras, leituras, visitas a empresas, simulações e realização de projetos, planos de negócios, vivências com empreendedores, entre outros (FILION, 2000; HONIG, 2004; SOUZA et al. 2004; KURATKO, 2005; HENRIQUE; CUNHA, 2008; DEGEN, 2009; GREATTI et al. 2010; ILANDER, 2010; LOPES, 2010; KNOTTS, 2011; BOYLES, 2012; SCHMIDT; SOPER; FACCA, 2012; ROCHA; FREITAS, 2014).

Considerando a necessidade de abordagem multidisciplinar imposta pelo empreendedorismo, envolvendo diversos conteúdos de aprendizagem, faz-se necessário organizar as metodologias e suas respectivas aplicações pedagógicas. Em virtude disto e das propostas pedagógicas constantes da literatura científica, é necessário relacionar e descrever
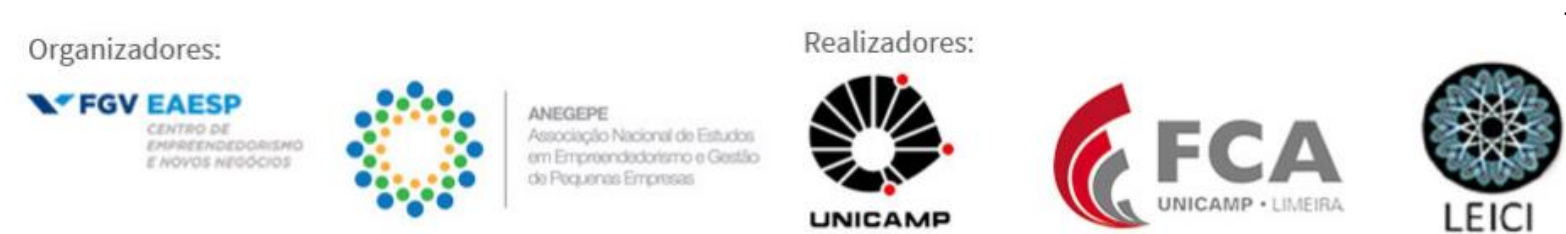
as aplicações dos principais métodos, técnicas e recursos utilizados no ensino do empreendedorismo. Tal ação visa despertar e fomentar o desenvolvimento de características de intenção, potencial e competências empreendedoras nos discentes, para que estes possam, num futuro próximo, tornar-se agentes empreendedores.

\subsection{Potencial Empreendedor}

Com intuito de compreender o perfil do potencial empreendedor do indivíduo que empreende, o empreendedorismo apresenta-se como tema de ampla difusão no ambiente acadêmico e se constitui como foco central de livros, artigos e publicações diversas. Esta necessidade já foi motivo de questionamentos anteriores por parte dos pesquisadores. Nesse sentido, diversas escalas já foram construídas visando identificar e mensurar o perfil do potencial empreendedor, através da aplicação de testes e, durante algum tempo, os estudos no campo do empreendedorismo estiveram voltados para a pergunta: quem é o empreendedor? (GARTNER, 1989; CARLAND; CARLAND; HOY, 1998; VEIT; GONÇALVES FILHO, 2007; SANTOS, 2008; SANTOS; CAETANO; CURRAL, 2010).

Segundo Culti-Gimenez et al. (2006) nos estudos de empreendedorismo alguns autores consideram os indivíduos prontos a serem estimulados à geração de novos valores, pois seriam empreendedores natos. Em virtude disso, Carland, Carland e Hoy (1992), propuseram um modelo conceitual com intuito de classificar o empreendedor em categorias, o método CEI - Carland Entrepreneurship Index.

O instrumento considera quatro construtos: Traços de Personalidade, Propensão à Inovação, Propensão ao Risco e Postura Estratégica, resultando numa escala com 33 (trinta e três) pares de questões. A dimensão Traços de Personalidade (TP), refere-se à necessidade de realização (NR) e criatividade. Culti-Gimenez et al. (2006) definem esta dimensão como uma motivação social, segundo os autores o indivíduo com elevada necessidade de realização é alguém que busca realizar atividades complexas, visa o atingimento de metas difíceis, segundo altos níveis de desempenho e esforça-se visando a excelência.

Segundo Freitas et al. (2009), a dimensão Propensão à Inovação (PI), busca compreender se o empreendedor agrega inovação em seus empreendimentos. Já a dimensão Propensão ao Risco (PR), se relaciona com os desafios enfrentados na busca dos objetivos sendo também é considerada pertinente ao empreendedor assim como a PI. Para CultiGimenez et al. (2006, p. 3) tal dimensão pode ser entendida como "a tendência e desejo do indivíduo em aceitar ou evitar situações de incerteza relativa a uma situação em que os resultados podem ser negativos ou positivos". Por a Postura Estratégica (PE), mede a capacidade de percepção do indivíduo em relação aos negócios, bem como a exploração de oportunidades (CARLAND; CARLAND, 1996).

De acordo com o modelo CEI, a classificação dos empreendedores baseia-se nos objetivos esperados para o negócio. A escala fundamenta-se em um meio de mensuração do potencial empreendedor de um indivíduo através da constatação da presença de determinadas características. Segundo esta perspectiva, todos os indivíduos que possuem tais características são empreendedores e, o que os diferencia é apenas a intensidade, podendo ser classificados em três grupos: microempreendedor, empreendedor e macro empreendedor.

Os microempreendedores ( 0 a 15 pontos da escala), percebem a organização como mais um aspecto de sua vida e cujo principal propósito é proporcionar o auto emprego e renda

\section{Organizadores:}
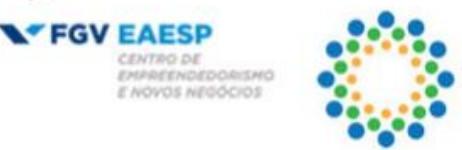

ANEGEPE
AsEociaglo

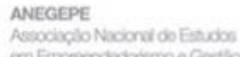

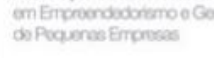

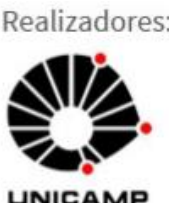

UNICAMP
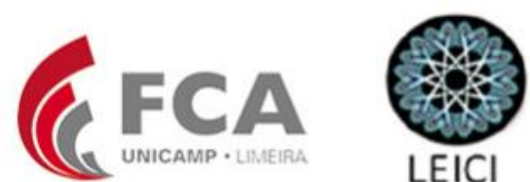
suficiente para ter liberdade e usufruir com a família e amigos. Já os empreendedores (16 a 25 pontos), possuem sonhos de reconhecimento por parte da sociedade, riqueza e liberdade. Por fim, os macros empreendedores ( 26 a 33 pontos) desejam tornar seu empreendimento o líder no setor, valorizando o reconhecimento social e riqueza, em detrimento do tempo livre e aspectos familiares (CULTI-GIMENEZ et al., 2006).

O instrumento não visa identificar que é ou não empreendedor, mas busca posicionar o indivíduo dentro de um "continuum" de pessoas mais ou menos empreendedoras (INÁCIO JÚNIOR; GIMENEZ, 2004). Pode-se então considerar que todos os indivíduos possuem características empreendedoras e o que os diferencia seria o nível de intensidade e aproveitamento destas características, visto que por se tratarem de personalidade e postura, enquadram-se como atributos subjetivos. Assim, quantificar um atributo subjetivo não se constitui em uma atividade fácil, de forma que não existe um único ou melhor instrumento. Neste estudo, adota-se o CEI como referência para tal quantificação.

\section{Metodologia da Pesquisa}

A pesquisa é de caráter descritivo, realizada por meio de uma survey de abordagem quantitativa dos dados e qualitativa no que diz respeito à análise dos planos de ensino. Quanto aos fins, a pesquisa é descritiva, visto que busca analisar o potencial empreendedor dos alunos do curso de Administração, de uma IES privada, segundo o modelo do Carland Entrepreneurship Index (CEI). Trata-se de um estudo quantitativo com aporte qualitativo através de pesquisa documental junto aos planos de ensino das disciplinas ministradas no curso em análise. Creswell (2010, p. 26) define a pesquisa quantitativa como "um meio para testar teorias objetivas, examinando a relação entre as variáveis. Tais variáveis, por sua vez, podem ser medidas tipicamente por instrumentos, para que os dados numéricos possam ser analisados por procedimentos estatísticos". De acordo com Richardson (2008) esse método é utilizado para identificar a existência de correlação entre variáveis, permitindo, em alguns casos, analisar, também a intensidade do relacionamento entre elas.

A população deste estudo é composta por 230 discentes do curso de Administração, de uma instituição de ensino superior privada do Ceará. O questionário foi aplicado junto a 171 alunos que estavam presentes em sala de aula no momento da realização da pesquisa. $\mathrm{O}$ retorno foi de $87,72 \%$, representando 150 questionários válidos para a pesquisa. Foram expurgados 21 questionários em função de estarem incompletos e com dados ausentes. Tais questionários foram desconsiderados e excluídos da pesquisa, visto que, nas análises que envolvem média padrão e cruzamento de dados, a ausência de dados, ou respostas incompletas, causam distorção nos resultados.

Visando identificar quais disciplinas do curso possuíam foco em empreendedorismo ou que abordassem esta temática, bem como categorizar as estratégias de ensino das mesmas, foi realizada uma pesquisa documental por meio da verificação e análise dos planos de ensino da IES pesquisada. Os dados foram analisados a fim de identificar as disciplinas que abordam a temática de empreendedorismo, quais as estratégias empregadas em cada uma e assim identificar quais as estratégias em comum.

Para identificar o perfil dos alunos e classificar o potencial empreendedor dos mesmos segundo a escala CEI (Carland Entrepreneurship Index), foi aplicado o instrumento elaborado por Carland; Carland e Hoy, (1992) que foi traduzido e validado no Brasil por
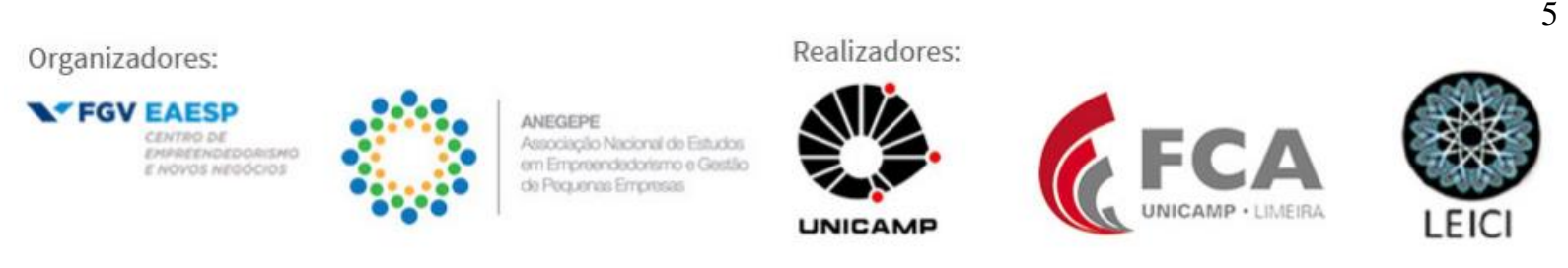
Inácio Júnior e Gimenez, em 2004. O CEI é composto por 33 (trinta e três) pares de questões que medem o potencial empreendedor segundo as quatro dimensões definidas pelos autores e já anteriormente citadas. O instrumento aplicado nesta pesquisa foi composto por dois blocos, um primeiro bloco buscando informações que visam traçar o perfil dos estudantes contendo perguntas de cunho relativo a: faixa etária, gênero, atividade profissional e intenção de empreender; e um segundo bloco contemplando as questões do instrumento de Carland; Carland e Hoy, (1992).

Os dados quantitativos foram obtidos por meio da aplicação do instrumento CEI e tabulados de acordo com o recomendado por Inácio Júnior e Gimenez (2004). Conforme escolha dos respondentes em relação as opções das questões e consequente soma de resultados, os indivíduos são classificados na escala CEI: microempreendedores ( 0 a 15 pontos), empreendedores (16 a 25 pontos) e macro empreendedores ( 26 a 33 pontos).

A análise dos dados quantitativos foi realizada por meio do tratamento das questões objetivas utilizando-se testes estatísticos executados a partir do software SPSS - Statistical Package for the Social Sciences - versão 20. Os dados coletados proporcionaram a elaboração de tabelas e realização da análise descritiva, objetivando a análise e compreensão de cada dado da pesquisa. Visto que ao descrever uma amostra o pesquisador tem a oportunidade de ter íntimo contato com os dados obtidos sendo possível antecipar-se aos problemas e identificar soluções prévias (MALHOTRA, 2006).

\section{Discussão de Resultados}

Nesta etapa serão apresentados os resultados da pesquisa obtidos por meio da análise dos planos de ensino do curso e aplicação dos questionários. Serão apresentadas, as estratégias de ensino adotadas pelas disciplinas do curso. No que diz respeito à segunda etapa da pesquisa - aplicação de questionário - a análise estatística foi realizada por meio da análise descritiva da amostra, análise de média, frequência, desvio padrão e coeficiente de variação.

\subsection{Estratégias de Ensino}

Os planos de ensino das disciplinas de todos os semestres do curso foram analisados, visando identificar quais delas continham algum conteúdo que abordassem temáticas de empreendedorismo e assim categorizar quais metodologias/estratégias de ensino eram utilizadas para trabalhar tais conteúdos em sala. Na IES objeto de estudo desta pesquisa, foram identificadas 17 disciplinas que abordam conteúdos que contribuem para formação empreendedora.

Tais disciplinas apresentam diferentes abordagens e estratégias adotadas pelos professores. Dentre as estratégias metodológicas utilizadas pela IES estudada, algumas delas se fazem presentes na maioria das disciplinas, destacando-se a aula expositiva, utilizada em todas as disciplinas listadas. Este resultado converge com os resultados Guimarães (2002). Segundo a autora, as aulas expositivas e leituras fazem-se necessárias para munir o aluno de informações sobre os processos de criação de empresas, bem como desenvolvimento de valores e atitudes necessários à prática empresarial.

Estratégias como: apresentação de seminário, estudo de caso, leituras e discussões de artigos/textos, exercícios e jogos, também são adotadas na maioria das disciplinas. Greatti et al. (2010) preconizam as estratégias de exercícios e jogos de simulação, quando afirmam que

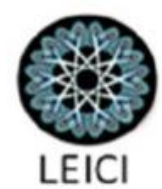


o ensino de empreendedorismo quando realizado em sala de aula deve priorizar as "metodologias problematizadoras", as quais levam o aluno a refletir sobre a solução de problemas, através da experimentação e relacionamento prático-teórico. Tais estratégias e abordagens são recomendadas em virtude da necessidade prática inerente ao ensino do empreendedorismo. Onde a vivência, adaptação, experimentação e inserção em contextos reais, fornece ao aluno o ambiente propício para o desenvolvimento de sua formação empreendedora, visto que este aprende fazendo (FILION, 2000; SOUZA et al., 2004; LAVIERI, 2010; LOPES, 2010, LIMA et al., 2014; ROCHA; FREITAS, 2014; LIMA et al., 2015).

\subsection{Classificação do Potencial Empreendedor}

Visando identificar o perfil dos discentes analisados, foram considerados aspectos como gênero, faixa etária, semestre do curso, se exerce ou não atividade remunerada e se possui intenção de abrir seu próprio negócio. $\mathrm{Na}$ amostra analisada, maioria é formada por homens (62,67\%), na faixa etária de 20 a 24 anos (47,33\%), cursando até a metade do curso (semestres 1 a 4; 62,7\%), onde 68,67\% declarou exercer alguma atividade remunerada, apenas $10 \%$ possui empresa, porém dentre os que não possuem (135 indivíduos), 115 afirmaram ter intenção de empreender (76,75\%). Quando questionados sobre a que atribuíam sua intenção empreendedora 44,5\% atribuíram ao ensino universitário, 33,6\% ao convívio familiar e $21,8 \%$ ao convívio com amigos.

Este estudo adotou como modelo teórico para a classificação do potencial empreendedor dos respondentes o Carland Entrepreneurship Index (CEI). Este modelo considera quatro dimensões de características para definir o potencial empreendedor, sendo elas: Postura Estratégica (PE), Propensão à Inovação (PI), Traços de Personalidade (TP) e Propensão ao Risco (PR).

Segundo Carland e Carland (1996), a Postura Estratégica (PE), verifica como o indivíduo utiliza sua percepção e intuição para solução de problemas. Neste sentido, as características verificadas nesse construto dizem respeito ao quanto o indivíduo é capaz de perceber oportunidades, tomar decisões, negociar e fazer com que as coisas aconteçam com uma economia de movimento. A Tabela 1 apresenta as características empreendedoras relacionadas ao construto Postura Estratégica (PE) investigadas junto aos respondentes desta pesquisa. 
Tabela 1 - Mapa das Características Empreendedoras dos Respondentes - Postura Estratégica (PE)

\begin{tabular}{l|c|c|c|c|c}
\hline \multirow{2}{*}{ Construto } & \multirow{2}{*}{$\begin{array}{c}\text { Questões } \\
\text { CEI }\end{array}$} & \multicolumn{2}{c|}{$\begin{array}{c}\text { Respostas SEM } \\
\text { Características }\end{array}$} & \multicolumn{2}{c}{$\begin{array}{c}\text { Respostas COM } \\
\text { Características }\end{array}$} \\
\cline { 3 - 6 } & 1 & Frequência & \% & Frequência & \% \\
\hline Postura Estratégica & 56 & 37,30 & 94 & 62,70 \\
Postura Estratégica & 4 & 13 & 8,70 & 137 & 91,30 \\
Postura Estratégica & 5 & 44 & 29,30 & 106 & 70,70 \\
Postura Estratégica & 8 & 13 & 8,70 & 137 & 91,30 \\
Postura Estratégica & 9 & 89 & 59,30 & 61 & 40,70 \\
Postura Estratégica & 11 & 55 & 36,70 & 95 & 63,30 \\
Postura Estratégica & 12 & 37 & 24,70 & 113 & 75,30 \\
Postura Estratégica & 20 & 48 & 32,00 & 102 & 68,00 \\
Postura Estratégica & 21 & 118 & 78,70 & 32 & 21,30 \\
Postura Estratégica & 23 & 42 & 28,00 & 108 & 72,00 \\
Postura Estratégica & 24 & 66 & 44,00 & 84 & 56,00 \\
Postura Estratégica & 27 & 57 & 38,00 & 93 & 62,00 \\
Postura Estratégica & 28 & 84 & 56,00 & 66 & 44,00 \\
\hline
\end{tabular}

Fonte: Dados da pesquisa

A partir da Tabela 1, nas respostas com características empreendedoras observa-se que as questões 4, "eu gostaria que este negócio crescesse e se tornasse uma empresa forte" e 8, "um plano deveria ser escrito para ser efetivo" se sobressaem, ambas com 91,3\% de frequência, ocupando a primeira posição no ranking de respostas. Na segunda posição, com $75,3 \%$ de frequência, encontra-se a questão 12, "eu seria aquele que tem de pensar e planejar". Estes resultados reafirmam os achados de Penz et al. (2014) e Tormen et al. (2015), visto que em suas pesquisas as questões 4 e 8 também aparecem entre as 3 primeiras colocações. Ainda na Tabela 1 são demonstradas as respostas sem características empreendedoras relativas ao construto Postura Estratégica (PE) traçadas a partir do CEI. Neste quesito, destaca-se a questão 21, "nada sobre gerenciar um negócio é sempre rotina", com 78,7\% ocupando o primeiro lugar destes itens do referido construto. A segunda posição é ocupada pela questão 9, "eu dividiria meu tempo entre este negócio, família e amigos" com $59,3 \%$ de frequência. Tais resultados corroboram com achados de Penz et al. (2014) e Tormen et. al. (2015).

Para Culti-Gimenez et al. (2006) a dimensão Propensão à Inovação (PI), pode ser considerada esta dimensão como condição fundamental ao ato de empreender, sendo condição fundamental ao reconhecimento de oportunidades no que diz respeito à criatividade e melhoria do negócio como um todo. Freitas et. al. (2009, p. 4), afirmam que a Propensão à Inovação (PI), enquanto dimensão do CEI, investiga se "o indivíduo empreendedor incorpora a inovação em sua ação de empreender". Na Tabela 2 são apresentadas as características empreendedoras relacionadas ao construto Propensão à Inovação (PI), obtidas por meio deste estudo.
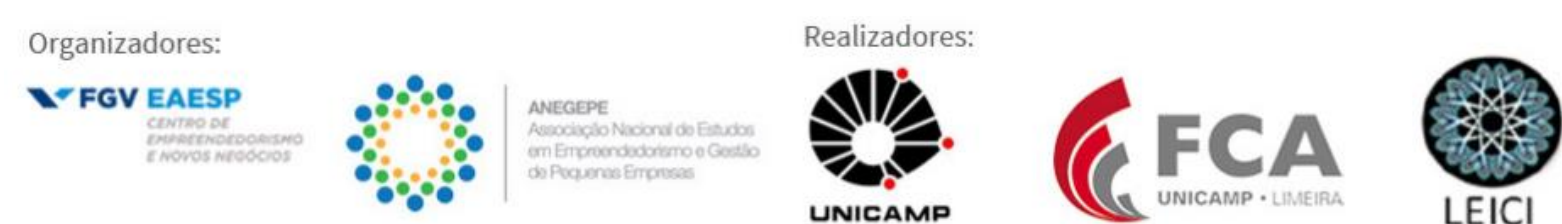
Tabela 2 - Mapa das Características Empreendedoras dos Respondentes - Propensão à Inovação (PI)

\begin{tabular}{l|c|c|c|c|c}
\hline \multirow{2}{*}{ Construto } & \multirow{2}{*}{$\begin{array}{c}\text { Questões } \\
\text { CEI }\end{array}$} & \multicolumn{2}{c|}{$\begin{array}{c}\text { Respostas SEM } \\
\text { Características }\end{array}$} & \multicolumn{2}{c}{$\begin{array}{c}\text { Respostas COM } \\
\text { Características }\end{array}$} \\
\cline { 3 - 6 } & 17 & Frequência & \% & Frequência & $\%$ \\
\hline Propensão à Inovação & 19 & 64 & 42,70 & 86 & 57,30 \\
Propensão à Inovação & 22 & 105 & 44,70 & 83 & 55,30 \\
Propensão à Inovação & 25 & 46 & 70,00 & 45 & 30,00 \\
Propensão à Inovação & 33 & 45 & 30,70 & 104 & 69,30 \\
Propensão à Inovação & \multicolumn{2}{|c|}{} & 47 & 105 & 70,00 \\
\hline
\end{tabular}

Fonte: Dados da pesquisa

Conforme Tabela 2, nas respostas com características empreendedoras observa-se que a questão 33, "é mais importante ver possibilidades nas situações", destaca-se com frequência de $70 \%$ dos respondentes. O segundo lugar é ocupado pela questão 25 , "eu adoro a ideia de tentar ser mais esperto que os concorrentes", com 69,30\% de resposta entre os indivíduos da amostra. Já nas respostas sem características empreendedoras, a questão 22, "eu prefiro pessoas que são realistas", atingiu o maior número de respostas (70\%). Seguida pelas questões 19, “eu penso que procedimentos operacionais padrões são cruciais" e 17 "eu procuro estabelecer procedimentos padrões para que as coisas sejam feitas certas", que alcançaram $19,44 \%$ e $17,42 \%$ respectivamente. Tais resultados confirmam os achados de Tormen et. al. (2015) e corroboram parcialmente com os de Penz et. al. (2014).

No que tange ao construto Traços de Personalidade (TP), também denominado de necessidade de realização, Culti-Gimenez et al. (2006) o definem como sendo uma motivação social. Assim, o indivíduo que apresenta elevada necessidade de realização, demonstra o desejo de realizar tarefas difíceis, buscando atingir metas ousadas, com esforço contínuo a fim de manter um elevado padrão de desempenho. A Tabela 3 retrata as características empreendedoras relacionadas ao construto Traços de Personalidade (TP), obtidas por meio deste estudo.

Tabela 3 - Mapa das Características Empreendedoras dos Respondentes - Traços de Personalidade (TP)

\begin{tabular}{l|c|c|c|c|c}
\hline \multirow{2}{*}{ Construto } & \multirow{3}{*}{$\begin{array}{c}\text { Questões } \\
\text { CEI }\end{array}$} & \multicolumn{2}{|c|}{$\begin{array}{c}\text { Respostas SEM } \\
\text { Características }\end{array}$} & \multicolumn{2}{c}{$\begin{array}{c}\text { Respostas COM } \\
\text { Características }\end{array}$} \\
\cline { 3 - 6 } & 2 & Frequência & \% & Frequência & \% \\
\hline Traços de Personalidade & 62 & 41,30 & 88 & 58,70 \\
Traços de Personalidade & 3 & 86 & 57,30 & 64 & 42,70 \\
Traços de Personalidade & 6 & 68 & 45,30 & 82 & 54,70 \\
Traços de Personalidade & 7 & 25 & 16,70 & 125 & 83,30 \\
Traços de Personalidade & 10 & 44 & 29,30 & 106 & 70,70 \\
Traços de Personalidade & 13 & 116 & 77,30 & 34 & 22,70 \\
Traços de Personalidade & 14 & 82 & 54,70 & 68 & 45,30 \\
Traços de Personalidade & 15 & 87 & 58,00 & 63 & 42,00 \\
Traços de Personalidade & 16 & 51 & 34,00 & 99 & 66,00 \\
Traços de Personalidade & 18 & 91 & 60,70 & 59 & 39,30 \\
Traços de Personalidade & 29 & 75 & 50,00 & 75 & 50,00 \\
Traços de Personalidade & 32 & 71 & 47,30 & 79 & 52,70 \\
\hline
\end{tabular}

Fonte: Dados da pesquisa 
Conforme demonstrado na Tabela 3, observa-se, nas respostas com características empreendedoras, que a questão 7, "eu não descansaria até que nós fossemos os melhores", ocupa o primeiro lugar nos itens deste construto segundo os respondentes, com $83,3 \%$ de frequência. Em segundo lugar está a questão 10, "eu tendo a deixar minha cabeça governar meu coração", com 70,7\% de resposta entre os indivíduos da amostra. Os resultados obtidos neste estudo corroboram parcialmente com os estudos de Penz et al. (2014) e Tormen et al. (2015).

Nas questões sem característica empreendedoras do construto Traços de Personalidade (TP), a primeira posição é ocupada pela questão 13, "as pessoas que trabalhassem para mim, gostariam de mim" com $77,3 \%$. Seguida pelas questões 18 , "eu penso que é importante ser otimista", e 3 "eu não iniciaria este negócio se eu não tivesse certeza de que seria bemsucedido", com $60,7 \%$ e $57,3 \%$ de frequência de respostas respectivamente. Tais resultados corroboram parcialmente com os achados de Tormen et al. (2015), pois os mesmos obtiveram maiores respostas nas questões 15, 3 e 13. Já com relação ao trabalho de Penz et al. (2014) a convergência de resultados encontra-se apenas na questão 13, que ocupa o terceiro lugar na pesquisa dos autores.

Por fim, a escala CEI apresenta o construto Propensão ao Risco (PR), que para Freitas et al. (2009), esta dimensão está associada à possibilidade de que um evento não ocorra conforme o planejado. Esta característica é considerada como inerente ao empreendedor, visto que conceber e gerir um empreendimento é, por si só, uma atividade arriscada. Neste sentido, a dimensão Propensão ao Risco (PR), investiga uma maior propensão de ousar ou arriscar. A Tabela 4 retrata as características empreendedoras relacionadas ao construto Traços de Personalidade (TP), obtidas por meio deste estudo.

Tabela 4 - Mapa das Características Empreendedoras dos Respondentes - Propensão ao Risco (PR)

\begin{tabular}{l|c|c|c|c|c}
\hline \multirow{2}{*}{ Construto } & \multirow{2}{*}{$\begin{array}{c}\text { Questões } \\
\text { CEI }\end{array}$} & \multicolumn{2}{|c|}{$\begin{array}{c}\text { Respostas SEM } \\
\text { Características }\end{array}$} & \multicolumn{2}{c}{$\begin{array}{c}\text { Respostas COM } \\
\text { Características }\end{array}$} \\
\cline { 3 - 6 } & 26 & Frequência & \% & Frequência & \% \\
\hline Propensão ao Risco & 57 & 38,00 & 93 & 62,00 \\
Propensão ao Risco & 30 & 12 & 8,00 & 138 & 92,00 \\
Propensão ao Risco & 31 & 50 & 33,30 & 100 & 66,70 \\
\hline
\end{tabular}

Fonte: Dados da pesquisa

A partir da Tabela 4, verifica-se que nas questões onde os respondentes apresentam características empreendedoras o primeiro lugar é ocupado pela questão 30, "se você que quer um negócio cresça, você tem que assumir alguns riscos", com $92 \%$ de frequência. Seguido pela questão 31, "eu realmente não sentiria falta de trabalhar para alguém", com $66,7 \%$. Tais resultados corroboram parcialmente com achados de Penz et al. (2014) e Tormen et al. (2015), visto que em ambos estudos a questão 30 ocupou o primeiro lugar entre as respostas dos seus entrevistados.

No que diz respeito às respostas sem características empreendedoras, a questão 26 , "a melhor abordagem é evitar o risco tanto quanto possível" encontra-se em primeiro lugar, com $38 \%$ de frequência. Já o segundo lugar, com 33,3\%, pertence à questão 31 , "a coisa que eu mais sentiria falta em trabalhar para alguém seria a segurança”. Estes resultados corroboram parcialmente com os encontrados por Penz et al. (2014) e Tormen et al. (2015), pois em
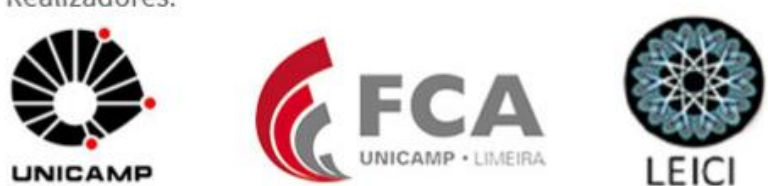
ambos achados a questão 31 ocupa posição entre o primeiro e segundo lugar na escolha dos respondentes.

No que diz respeito aos resultados da amostra no CEI, os indivíduos apresentam potencial empreendedor médio de 19,73 pontos, o que os coloca acima da média teórica da escala (16,5), desvio padrão de 3,51, mediana 20 e moda 19. A distribuição dos resultados da amostra no CEI apresentou valor mínimo de 11 pontos e máximo de 30 pontos. Ao distribuir os respondentes nas três classificações existentes na escala obteve-se: a) 127 empreendedores $(84,67 \%)$; b) 16 microempreendedores $(10,67 \%)$ e c) 7 macros empreendedores $(4,67 \%)$.

Constata-se que a aplicação da escala CEI junto aos estudantes do curso de administração de uma instituição de ensino superior privada no Ceará, além de revelar o perfil empreendedor dos discentes conforme a escala utilizada, também corrobora parcialmente com os estudos de Inácio Junior e Gimenez (2004), Culti-Gimenez et al. (2006), Penz et al. (2014) e Tormen et al. (2015).

Assim, uma vez identificado o potencial empreendedor dos respondentes, buscou-se estabelecer relações entre as variáveis visando identificar se uma alguma característica do perfil do indivíduo propicia determinado potencial empreendedor. Para tanto, foi utilizada a técnica estatística de Análise de Variância (ANOVA). De acordo com Hair et al. (2009, p. 304), utiliza-se a ANOVA quando o objetivo é "determinar se as amostras de dois ou mais grupos surgem de populações com médias iguais". Neste sentido, o que se busca é identificar se as médias dos grupos diferem significativamente.

Desta forma, o potencial empreendedor foi estabelecido como variável dependente e as variáveis independentes foram: gênero, idade, semestre do curso, possuir ocupação, possuir empresa, intenção de abrir empresa e participação em oficinas ofertadas pela IES. Na sequência, a Tabela 5 resume os valores de $\mathrm{p}$.

Tabela 5 - ANOVA para Características de Perfil x Potencial Empreendedor

\begin{tabular}{lccccc}
\hline \multicolumn{1}{c}{ Caracteristica } & $\begin{array}{c}\text { Soma dos } \\
\text { Quadrados }\end{array}$ & df & $\begin{array}{c}\text { Média dos } \\
\text { Quadrados }\end{array}$ & F & Sig. \\
\hline Gênero & 32,35 & 1 & 32,35 & 2,66 & 0,105 \\
Idade & 118,91 & 6 & 19,82 & 1,66 & 0,136 \\
Semestre & 141,19 & 7 & 20,17 & 1,69 & 0,115 \\
Trabalha/Não & 1,36 & 1 & 1,36 & 0,11 & 0,741 \\
$\begin{array}{l}\text { Possui empresa } \\
\begin{array}{l}\text { Intenção abrir } \\
\text { empresa }\end{array}\end{array}$ & 1,93 & 1 & 1,93 & 0,16 & 0,694 \\
$\begin{array}{l}\text { Participação em } \\
\text { oficinas }\end{array}$ & 20,48 & 2 & 10,24 & 0,83 & 0,438 \\
& 0,40 & 1 & 0,40 & 0,03 & 0,857
\end{tabular}

Fonte: Dados da pesquisa

Considerando o valor de p como 5\%, as características de perfil acima listadas foram individualmente analisadas. Isto feito, constatou-se que os resultados obtidos não apresentaram diferenças estatísticas entre os três níveis de potencial empreendedor dos respondentes. Desta forma, não é possível afirmar que as características de perfil analisadas e a participação em oficinas de formação oferecidas pela IES, apresentam influência sobre o

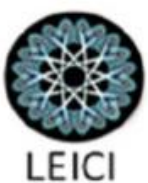


potencial empreendedor dos indivíduos inqueridos na pesquisa. Após a conclusão das análises dos dados oriundos da pesquisa, o capítulo a seguir versa sobre as considerações finais deste estudo.

\section{Considerações Finais}

Este estudo buscou, através do Carland Entrepreneurship Index - CEI e da verificação dos planos de ensino das disciplinas ofertadas aos estudantes, analisar a contribuição do ensino de empreendedorismo no desenvolvimento do potencial empreendedor dos estudantes do curso de Administração de uma instituição de ensino superior privada no Ceará. A amostra foi composta por 171 estudantes. A metodologia utilizada foi uma survey de abordagem quantitativa dos dados e qualitativa no que diz respeito à análise dos planos de ensino. Desta forma, a coleta de dados foi realizada junto aos planos de ensino das disciplinas que possuem conteúdos relacionados ao empreendedorismo e aplicação do instrumento de pesquisa proposto por Carland, Carland e Hoy (1992), traduzido e validado por Inácio Júnior e Gimenez (2004). O instrumento é composto por 33 pares de questões fechadas que medem o potencial empreendedor segundo quatro dimensões: traços de personalidade $(\mathrm{TP})$, propensão à inovação (PI), propensão ao risco (PR) e a postura estratégica (PE). A análise dos dados coletados fez uso de estatística descritiva e planilhas eletrônicas.

Os planos de ensino das disciplinas de todos os semestres do curso foram analisados, visando identificar quais delas continham algum conteúdo que abordassem temáticas de empreendedorismo e assim categorizar as estratégias de ensino utilizadas para trabalhar tais conteúdos em sala. Por meio da análise, foram identificadas 17 disciplinas que abordam conteúdos que contribuem para formação empreendedora e que utilizam diversas metodologias de ensino, onde destacam-se: aulas expositivas, apresentação de seminário, estudo de caso, leituras e discussões de artigos/textos, exercícios e jogos. No que diz respeito ao perfil da amostra, quanto ao gênero constata-se que a maioria é formada por homens $(62,67 \%)$, na faixa etária de 20 a 24 anos (47,33\%). Ressalta-se que 68,67\% declarou exercer alguma atividade remunerada e apenas $10 \%$ possui empresa, porém dos 135 indivíduos que não possuem, 115 afirmaram ter intenção de empreender.

Com relação aos construtos medidos por meio do CEI, constatou-se a presença das quatro dimensões propostas pelos autores, sendo: Postura Estratégica (PE); Propensão ao Risco (PR); Traços de Personalidade (TP) e Propensão à Inovação (PI). Ressalta-se que estes achados corroboram com os resultados de Penz et. al. (2014) e Tormen et. al. (2015). No que diz respeito à classificação do potencial empreendedor conforme o CEI, observa-se a predominância de indivíduos classificados como empreendedores, 84,66\%. Segundo o referencial teórico, estes indivíduos ao empreenderem, buscam lucratividade e evolução do seu empreendimento. No entanto, por estarem faixa intermediária da escala, seu comportamento é de difícil previsibilidade. A segunda classificação de potencial empreendedor mais encontrada foi a de microempreendedores, com 10,67\% da amostra. Em seus empreendimentos estes indivíduos buscam o auto emprego, qualidade de vida, além de sustento pessoal e familiar. Os macros empreendedores constituíram 4,67\% da amostra, os indivíduos enquadrados neste nível da escala CEI caracterizam-se por buscar ser o primeiro do mercado em que atua através de uma postura inovadora e criativa, deseja recompensas sociais e financeiras em virtude da realização de seu empreendimento.
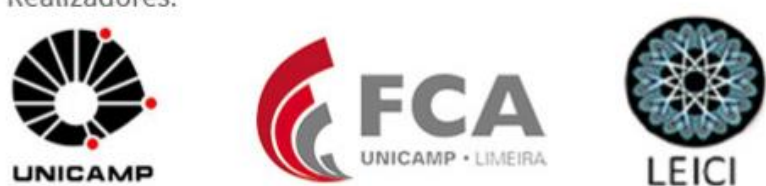
A Análise de Variância (ANOVA) foi realizada visando identificar se uma alguma característica do perfil do indivíduo, propiciava determinado potencial empreendedor. No entanto, com um $p$ de 5\%, os resultados obtidos não apresentaram diferenças estatísticas entre os três níveis de potencial empreendedor dos respondentes. Tais resultados indicam normalidade entre os dados. Desta forma, não é possível afirmar que as características de perfil analisadas, influenciam nos resultados de potencial empreendedor encontrados neste estudo.

Os resultados da pesquisa demonstram que a metodologia de trabalho dos docentes das disciplinas de empreendedorismo necessita de um grau de empenho maior que o papel tradicional do professor universitário. As metodologias ativas devem ser preconizadas. $\mathrm{O}$ aluno necessita aprender fazendo, por meio da experimentação, reflexão e prática. Desta forma, o envolvimento pedagógico deve ser diferenciado neste processo de ensinoaprendizagem, buscando uma coerência maior com o papel que o empreendedor desempenha na sociedade.

No que concerne às limitações deste estudo, destaca-se o fato de que, em virtude da aplicação dos questionários ter ocorrido próximo ao período de avaliação da segunda etapa do semestre, muitos discentes não foram encontrados em sala de aula ou não estavam dispostos a responder a pesquisa com veracidade, o que resultou em 21 formulários $(12,28 \%)$, do total de 171, expurgados da amostra em função de estarem incompletos ou incorretamente preenchidos. Outro aspecto relevante é que, o potencial empreendedor foi medido através de um instrumento fechado e de autopreenchimento, que não leva em consideração bagagens anteriores dos indivíduos pesquisados. A aplicação de técnicas adicionais, como entrevistas com os participantes serviriam de comparação entre o CEI e o discurso dos indivíduos. Por fim, cabe ressaltar como limitação o fato de que as frequências de potencial Empreendedor (127), Microempreendedor (16) e Macro empreendedor (7), são muito diferentes entre si. Caso a Análise de Variância (ANOVA) fosse realizada com frequências similares proporcionaria resultados mais confiáveis ao estudo.

Sugere-se para pesquisas futuras a triangulação entre as visões do professor, aluno e coordenação de curso. Bem como a análise das intenções empreendedoras dos alunos que mencionarem a intenção de abrir seu próprio negócio, além de realização de um estudo longitudinal visando medir o potencial empreendedor e mapeamento as competências empreendedoras destes alunos após conclusão de seus cursos de graduação.

\section{Referências}

ANDREASSI, T.; FERNANDES, R. J. R. O uso das competições de planos de negócios como ferramenta de ensino de empreendedorismo. In: LOPES, R. M. A. (Orga.). Educação empreendedora: conceitos, modelos e práticas. Rio de Janeiro: Elsevier; São Paulo: Sebrae, 2010.

BERNHEIM, C. T.; CHAUI, M. S. A universidade e a sociedade do conhecimento. Desafios da universidade na sociedade do conhecimento. Brasília: Unesco, 2008.

BOYLES, T. 21st century knowledge, skills, and abilities and entrepreneurial competence: a model for undergraduate entrepreneurship education. Journal of Entrepreneurship Education, v. 15, p. 41-55, 2012.
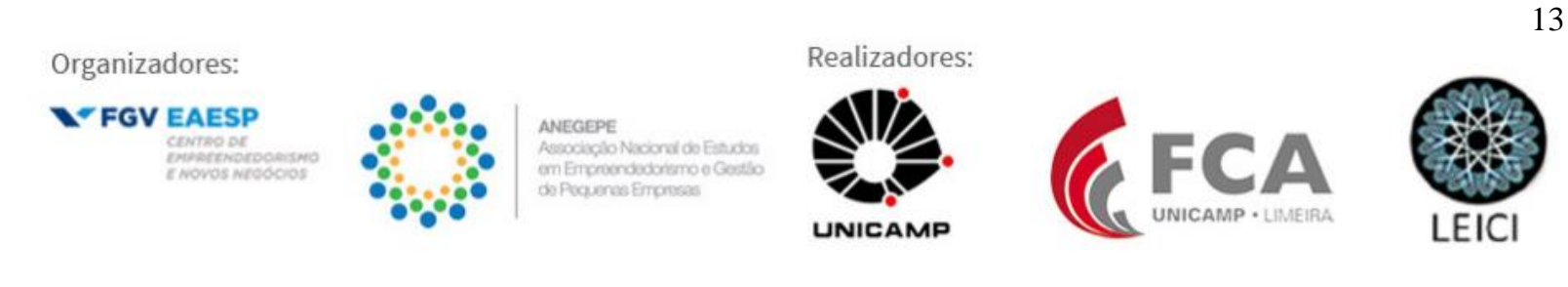
CARLAND, J. W; CARLAND, J. A.; HOY, F. S. An entrepreneurship Index: an empirical validation. Frontiers of Entrepreneurship Research, Boston, v. 25, n. 3, p. 244-265, Mar. 1992.

CARLAND J. W.; CARLAND, J. A. The Theoritetical Bases and Dimensionality of the Carland Entrepreneurship Index. Proceedings of the RISE 96 Conference, University of Jyvaskylâ, Finlândia, p. 1-24, 1996.

CARLAND, J. W; CARLAND, J. A.; HOY, F. S. Who is an Entrepreneur? Is a question worth asking? American Journal of Small Business. v. 15, n. 3, p. 33-39, Spring 1998.

CARREE, M. A.; THURIK, A. R. The impact of entrepreneurship on economic growth. 2003. Disponível em: < http://ondernemerschap.panteia.nl/pdf-ez/n200320.pdf > Acesso em: 29 jun. 2016.

COUTO, C. L. P. D.; MARIANO, S. R. H.; MAYER, V. F. Medição da Intenção Empreendedora no Contexto Brasileiro: desafios da aplicação de um modelo internacional. In: Encontro Nacional da Associação Nacional de Pós-Graduação e Pesquisa em Administração, 34., Rio de Janeiro, 2010. Anais... Rio de Janeiro: ANPAD, 2010.

CRESWELL, J. W. Projeto de Pesquisa: método qualitativo, quantitativo e misto. 3.ed. Porto Alegre: Artmed, 2010.

CULTI-GIMENEZ, S.; COSTA, M. I.; SCHYPUlA, A.; GIMENEZ, F. A. P. Comportamento empreendedor de alunos do curso de turismo. Cadernos da Escola de Negócios, v. 4, n. 4, jan./dez. 2006.

DEGEN, R. O empreendedor: empreender como opção de carreira. São Paulo: Pearson Prentice Hall, 2009.

FILION, L. J. Empreendedorismo: Ciência, Técnica e Arte. Brasília: CNI. IEL Nacional, 2000.

FONTENELE, R. E. S.; BRASIL, M. V. de O.; SOUSA, A. M. R. Determinantes da Intenção Empreendedora de Discentes em um Instituto de Ensino Superior. In: XXVII Simpósio de Gestão da Inovação Tecnológica, 27., Salvador, 2012. Anais... Rio de Janeiro: ANPAD, 2012.

FREITAS, A. A. F.; RIBEIRO, R. C. L.; BARBOSA, R. T.; PATRICIO, P. E. A. O potencial empreendedor de empreendedores informais clientes de programas de microcrédito: uma avaliação sob as perspectivas de capital humano e gênero. In: ENCONTRO DA ASSOCIAÇÃO NACIONAL DOS PROGRAMAS DE PÓS-GRADUAÇÃO EM ADMINISTRAÇÃO, 33., São Paulo, 2009. Anais... Rio de Janeiro: ANPAD, 2009. CDROM.

GARTNER, W. B. Who is an entrepreneur? Is the wrong question. Entrepreneurship Theory and Practice, v. 13, p. 47-68, 1989.

GREATTI, L.; GRALIK, E.; VIEIRA, F. G. D.; SELA, V. M. Aprendizagem em Empreendedorismo dos Acadêmicos do Curso de Administração de uma Universidade Estadual no Sul do Brasil. In: Encontro Nacional da Associação Nacional de Pós-Graduação e Pesquisa em Administração, 34., Rio de Janeiro, 2010. Anais... Rio de Janeiro: ANPAD, 2010.

GUIMARÃES, L. O. A experiência universitária norte-americana na formação de empreendedores. Contribuições das universidades de Saint Louis, Indiana e
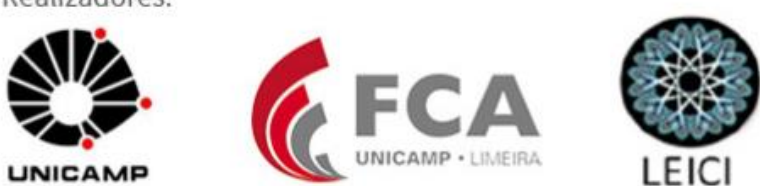
BabsonCollege. 2002. Tese (Doutorado em Administração) - Fundação Getúlio Vargas Escola de Administração de Empresas. São Paulo, 2002.

HAIR, J. F.; BLACK, W. C.; BABIN, B. J.; ANDERSON, R. E.; TATHAM, R. L. Análise Multivariada de Dados. 6 ed. Porto Alegre: Bookman, 2009.

HECKE, A. P. A Intenção Empreendedora dos Alunos Concluintes dos Cursos de Graduação em Administração e Ciências Contábeis das Instituições de Ensino Superior de Curitiba. 2011. Dissertação (Mestrado em Contabilidade) - Universidade Federal do Paraná. Curitiba, 2011.

HENRIQUE, D.C.; CUNHA, S.K. da. Práticas didático-pedagógicas no ensino de empreendedorismo em cursos de graduação e pós-graduação nacionais e internacionais. RAM-Rev. Adm. Mackenzie, São Paulo, vol. 9, n. 5, 2008.

HISRICH, R. D.; PETERS, M. P.; SHEPHERD, D. A., Empreendedorismo. 9. ed. Porto Alegre. Bookman, 2014.

HONIG, B. Entrepreneurship education: toward a model of contingency-based business planning. Academy of Management Learning and Education, v. 3, p. 258-273, 2004.

ILANDER, G. P. B. The use of feature films to promote entrepreneurship. International Journal Information and Operation Management Education, v. 3, p. 284-302, 2010.

INÁCIO JÚNIOR, E.; GIMENEZ, F. A. P. Potencial Empreendedor: um instrumento para mensuração. Revista de Negócios, v. 9,n. 2, p. 107-116, 2004.

KNOTTS, T. L. The SBDC in the classroom: providing experiential learning opportunities at different entrepreneurial stages. Journal of Entrepreneurship Education, v. 14, p. 25-38, 2011.

KURATKO, D. F. The emergence of entrepreneurship education: development, trends, and challenges. Entrepreneurship Theory and Practice, p. 577-598, v. 29, 2005.

LAVIERI, C. Educação...empreendedora? In: LOPES, R.M. A. (Org.). Educação empreendedora: conceitos, modelos e práticas. cap. 1. Rio de Janeiro: Elsevier; São Paulo: Sebrae, 2010.

LIMA, E.; LOPES, R. M.; NASSIF, V.; SILVA, D. Opportunities to Improve Entrepreneurship Education: Contributions Considering Brazilian Challenges. Journal of Small Business Management. 2014. Recuperado de: < https://www.researchgate.net/profile/Edmilson_Lima2/publication/261376054_Opportunities _to_Improve_Entrepreneurship_Education_Contributions_Considering_Brazilian_Challenges /links/00b495376bf21a57a2000000.pdf> Acesso em: 13 jul. 2016

LIMA, E.; LOPES, R. M. A.; NASSIF, V. M. J.; SILVA, D. Ser seu Próprio Patrão? Aperfeiçoando-se a Educação Superior em Empreendedorismo. RAC, Rio de Janeiro, v. 19, n. 4, art. 1, p. 419-439, Jul./Ago. 2015

LIMA, E.; HASHIMOTO M.; MELHADO J.; ROCHA, R. Caminhos para uma Melhor Educação Superior em Empreendedorismo no Brasil. XXXVIII Encontro da ANPAD, Rio de Janeiro, set/2014.

LOPES, R. M. A. Educação empreendedora: conceitos, modelos e práticas. São Paulo: Elsevier, 2010.2 Disponível em: $<$ https://books.google.com.br/books?id=5WOOyQ3qBtEC\&pg=PA67\&lpg=PA67\&dq=Educ a\% $3 \% \mathrm{~A} 7 \% \mathrm{C} 3 \% \mathrm{~A} 3 \mathrm{o}+\mathrm{empreendedora+nas+universidades+brasileiras+guerra+grazziotin \& so}$ urce=bl\&ots=bXihPMaqeC\&sig=0YJXIXwFbsc9dmohzdvVm3hXP_8\&hl=pt-
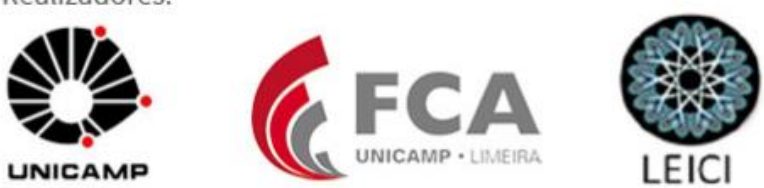
BR\&sa=X\&ved=0ahUKEwiS19TPs_bNAhUBkZAKHTYsD6cQ6AEILjAC\#v=onepage\&q= Educa $\% \mathrm{C} 3 \% \mathrm{~A} 7 \% \mathrm{C} 3 \% \mathrm{~A} 3 \mathrm{o} \% 20 \mathrm{empreendedora} \% 20$ nas $\% 20$ universidades $\% 20$ brasileiras $\% 20$ guerra\%20grazziotin\&f=false> Acesso em: 13 jul. 2016.

MALHOTRA, N. K. Pesquisa de marketing: uma orientação aplicada. 4. ed. Porto Alegre: Bookman, 2006.

MCCLELLAND, D. C. A sociedade competitiva: realização e progresso social. Rio de Janeiro: Editora Expressão e Cultura,1972.

PENZ, D.; AMORIM, B. C.; NASCIMENTO, S.; SILVEIRA, A. Potencial empreendedor dos discentes do curso de administração de uma instituição privada à luz do Carland Entrepreneurship Index (CEI). In: ENCONTRO DE ESTUDOS EM EMPREENDEDORISMO E GESTÃO DE PEQUENAS EMPRESAS, 8., 2014, Goiânia. Anais... Goiânia: EGEPE. 2014. CD-ROM.

ROCHA, E. L. C. R.; FREITAS A. A. F. Avaliação do Ensino de Empreendedorismo entre Estudantes Universitários por meio do Perfil Empreendedor. Revista de Administração Contemporânea RAC, Rio de Janeiro, v. 18, n. 4, art. 5, p. 465-486, jul/ago 2014.

RIBEIRO, P. E.; BERNARDES, M. A. O Papel da Universidade no Desenvolvimento do Comportamento Empreendedor em Regiões Carentes. Revista Eletrônica Gestão e Serviços, v. 5, n. 2, p. 978-993, Jul./Dez. 2014.

RICHARDSON, R. J. Pesquisa Social: métodos e técnicas. 3. ed. São Paulo: Atlas, 2008.

SANTOS, S. C.; CAETANO, A.; CURRAL, L. Atitude dos estudantes universitários face ao empreendedorismo. Revista Portuguesa e Brasileira de Gestão, v. 9, n. 4, p. 2-14, 2010.

SCHMIDT, J. S.; SOPER. J. C.; FACCA, T. M. Creativity in the entrepreneurship classroom. Journal of Entrepreneurship Education, v. 15, p. 123-131, 2012.

SCHUMPETER, J. A. Teoria do Desenvolvimento Econômico: uma investigação sobre lucros, capital, crédito, juro e o ciclo econômico. São Paulo: Abril Cultural, 1982 [1934]..Disponível em: < http://www.ufjf.br/oliveira_junior/files/2009/06/s_Schumpeter__Teoria_do_Desenvolvimento_Econ\%C3\%B4mico_-

_Uma_Investiga\%C3\%A7\%C3\%A3o_sobre_Lucros_Capital_Cr\%C3\%A9dito_Juro_e_Ciclo _Econ\%C3\%B4mico.pdf> Acesso em: 02 mai. 2016.

SILVA, G. S. Educação Empreendedora nas IES Cearenses: Um estudo

Multicaso. 2010. Dissertação (Mestrado em Administração) - Universidade de Fortaleza, Fortaleza, 2010.

SOUZA, E. C. L.; SOUZA, C.C.L.; ASSIS, S.A.G.; ZERBINI, T. Métodos e técnicas de ensino e recursos didáticos para o ensino do empreendedorismo em IES

brasileiras. EPA-1850. In: XXVIII Encontro da ANPAD, 28, Curitiba, 2004. Anais... Rio de Janeiro: ANPAD, 2004.

TORMEN, J.; NASCIMENTO, S. DO.; VERDINELLI, M. A.; LIZOTE, S. A.; Potencial Empreendedor dos Estudantes das Ciências Sociais Aplicadas de uma Instituição de Ensino Superior sob a Ótica do Carland Entrepreneurship Index (CEI). Revista ADMpg Gestão Estratégica, Ponta Grossa, v. 8, n. 2, p. 17-25, 2015.

VEIT, M. R; GONÇALVES FILHO, C. Mensuração do Perfil Empreendedor e seu impacto no desempenho das pequenas empresas. In: XXXI Encontro da ANPAD, 31., Rio de Janeiro, 2007. Anais... Rio de Janeiro: ANPAD, 2007. Disponível em: <http://www.anpad.org.br/admin/pdf/ESO-C1300.pdf> Acesso em: 18 jul. 2016.
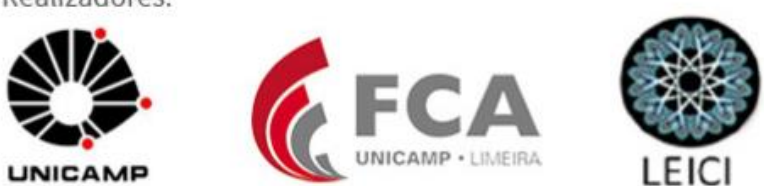